University of Wollongong

Research Online

Faculty of Informatics - Papers (Archive)

Faculty of Engineering and Information

Sciences

2008

\title{
An integrated approach of wavelet-rough set technique for classification of power quality disturbances
}

Chandrashekhar Bhende

University of Wollongong, uow@bhende.edu.au

Satya Mishra

Indian Institute of Technology - Delhi

Follow this and additional works at: https://ro.uow.edu.au/infopapers

Part of the Physical Sciences and Mathematics Commons

\section{Recommended Citation}

Bhende, Chandrashekhar and Mishra, Satya: An integrated approach of wavelet-rough set technique for classification of power quality disturbances 2008.

https://ro.uow.edu.au/infopapers/3226

Research Online is the open access institutional repository for the University of Wollongong. For further information contact the UOW Library: research-pubs@uow.edu.au 


\title{
An integrated approach of wavelet-rough set technique for classification of power quality disturbances
}

\author{
Abstract \\ This paper presents an integrated approach of wavelet and rough set theory for the classification of \\ power quality (PQ) disturbances. Further, the number of features and the rules required for proper \\ classification are decided through rough set approach. Moreover, as the proposed methodology can \\ reduce the number of features extracted through wavelet to a great extent, it will indirectly reduce the \\ memory requirement for the classification procedure. Eleven types of $P Q$ disturbances are considered for \\ classification. The simulation results show that the combination of wavelet and rough set theory can \\ effectively classify different power quality disturbances. Since rule based approach is easy to understand \\ and simple to implement, the rough set technique is a good candidate for the classification of PQ \\ disturbances.

\section{Disciplines} \\ Physical Sciences and Mathematics

\section{Publication Details} \\ C. N. Bhende \& S. Mishra, "An integrated approach of wavelet-rough set technique for classification of \\ power quality disturbances," in Harmonics and Quality of Power, 2008. ICHQP 2008. 13th International \\ Conference on, 2008, pp. 1-6.
}




\title{
An Integrated Approach of Wavelet-Rough Set Technique for Classification of Power Quality Disturbances
}

\author{
C. N. Bhende, Student Member, IEEE, S. Mishra, Senior Member, IEEE
}

\begin{abstract}
This paper presents an integrated approach of Wavelet and Rough Set Theory for the classification of power quality (PQ) disturbances. Further, the number of features and the rules required for proper classification are decided through Rough Set approach. Moreover, as the proposed methodology can reduce the number of features extracted through Wavelet to a great extent, it will indirectly reduce the memory requirement for the classification procedure. Eleven types of $P Q$ disturbances are considered for classification. The simulation results show that the combination of Wavelet and Rough Set Theory can effectively classify different power quality disturbances. Since rule based approach is easy to understand and simple to implement, the Rough Set technique is a good candidate for the classification of PQ disturbances.
\end{abstract}

Key words: Wavelet, Rough Set Theory, feature extraction, rule based classification of power quality disturbances.

\section{INTRODUCTION}

The quality of electric power has become an important issue for electric utilities and their customers. As a result, power quality (PQ) study is gaining interest. Degradation in quality of electric power is normally caused by power-line disturbances such as voltage sag/swell with and without harmonic, momentary interruption, harmonic distortion, flicker, notch, spike and transients, causing problems such as malfunctions, instabilities, short lifetime, failure of electrical equipments and so on. In electric power network system faults may cause voltage sag or momentary interruption whereas switching off of large load or energization of large capacitor bank may lead to voltage swell. On the other hand use of solid state switching devices, non-linear and power electronically switched loads such as rectifiers or inverters may cause harmonic distortion and notching in the voltage and current. Use of arc furnaces may lead to flickers. Ferroresonance, transformer energization, capacitor switching may cause transients and lightning strikes may lead to spikes.

In a realistic power system, to improve power quality these disturbances need to be identified before appropriate mitigating action can be taken so that the disturbance does not cause any adverse effect on the equipments or processes.

Generally PQ monitoring is carried out by capturing the disturbance based on visual inspection. As a result, power quality engineers are inundated with enormous amount of data to inspect. Moreover, they may loose the important information while monitoring. Hence, a robust method for automatic classification of disturbances is highly demanded.

C. N. Bhende is with School of Electrical, Computer \& Telecommunication Engg. (SECTE), University of Wollongong, Australia, and S. Mishra is with the Department of Electrical Engineering, IIT Delhi, India - 110016. (e-mail: cnbhende@rediffmail.com,sukumar@ee.iitd.ac.in).
Wavelet exhibits its notable capabilities for detection and localization the power disturbances [1-2]. In order to identify the type of PQ disturbance more effectively, several authors have presented different methodologies based on the combination of wavelet transform (WT) and artificial neural network (ANN) [3-6]. Using the features derived through WT and subsequently training with an ANN, it is possible to extract important information about the disturbance signal and to determine what type of disturbance has caused a power quality (PQ) problem to occur. The features mostly in use are time at which the disturbance occurs, slope or gradient of disturbed signal and energy distribution at various decomposition levels of wavelet. These features are used by the ANN for classification.

Neural network has the shortcoming of implicit knowledge representation. On the other hand, rule based classification gives better understanding of the classification procedure compared to the neural network based method. Moreover, since it is a set of rules we can modify it as and when required. Rough Set approach gives rule based classification which is quite easy and simple. Besides, the proposed methodology reduces the number of features extracted from WT to a great extent and hence the memory requirement will be less for the classification of the PQ events.

Recently Rough Sets Theory [7] has been successfully used in some of the areas of power system for event extraction [8], security assessment [9], power system control centre data mining [10], fault classification [11] and classification of power system operation points [12]. Rough Sets can handle the problem efficiently where large amounts of data are produced. Rough Sets Theory constitutes a framework for inducing minimal decision rules. These rules in turn can be used to perform the classification task. The main goal of the rough set analysis is to search large database for meaningful decision rules and finally acquire new knowledge. The rough set analysis gives a minimal set of attributes called as reduct which preserves the partitioning of the finite set of objects and therefore the original classes.

In this paper authors have used a combination of Wavelet [13-15] and Rough Set Theory for effective classification of 11 types of PQ disturbances. 13 features which are energy distribution at 13 decomposition levels of wavelet are extracted using Discrete Wavelet Transform [1, 6, 15]. The procedure for extracting the features is given in $[1,6]$ and hence, not included in this paper. The crisp values of the features are then converted into ranges and then Rough Set Theory is applied. These 13 features are reduced to 5 through attribute reduction technique. Finally with the reduced number of features, the rules are framed for classification. Since, less numbers of features are used for the classification of 11 types of PQ disturbances, the memory requirement and computational time will reduce. 


\section{OVERVIEW OF ROUGH SET THEORY}

The Rough Set Theory is a mathematical tool presented to dispose incomplete and uncertainty problem [7]. The analysis allows us to identify the relationship between the values of those significant variables (in the specified ranges) and the likelihood of the specified event occurring. It is important to discuss following definitions related to Rough Set Theory before proceeding for the problem formulation.

\section{A. Indiscernibility Relation}

The indiscernibility relation is used to reduce the dimensionality of large data set extracted from WT without losing original information. For each set of attributes, the indiscernibility relation partitions the set of events (elements of universe) into a family of equivalence classes. Equivalence classes are the elementary sets of our knowledge representation system. A knowledge representation system is a pair $S=(U, A)$, where

$U \rightarrow$ is a nonempty, finite set called the universe

$A \rightarrow$ is a nonempty, finite set of primitive attributes

Every subset of attributes $B$ in $A(B \subseteq A)$ in the knowledge system $S=(U, A)$ that determines a relation on $U$ is called indiscernibility relation which is formulated as

$$
\operatorname{IND}(B)=\left\{(x, y) \in U^{2}: \text { for every } a \in B, a(x)=a(y)\right\}
$$

where $a(x)$ denotes the value of attributes $a$ for the event $x$. If $(x, y) \in \operatorname{IND}(B)$, then the events $x$ and $y$ are indiscernible from each other with respect to the attribute $B$. The family of all the equivalence classes in the relation $\operatorname{IND}(B)$ will be denoted by $U / \operatorname{IND}(B)$. The indiscernibility relation preserves the equivalence classes and hence, the ability to form approximations [8].

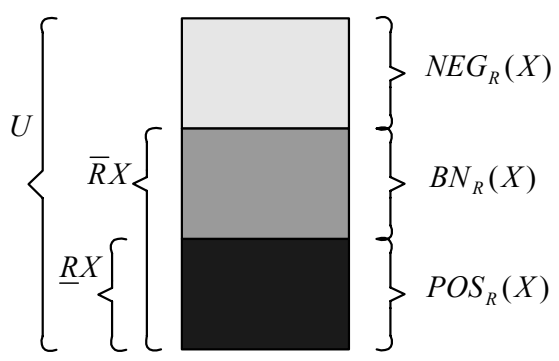

Fig. 1. Definition of rough set approximations

\section{B. Approximations}

The rough set approach to data analysis works with lower and upper approximation of a set as shown in Fig. 1. The discernibility relation is used for two basic operations in rough set theory i.e. upper $\bar{R} X$ and lower $\underline{R} X$ approximations, which defines crisp and vagueness present in the sets. If any concept of the universe can be formed as a union of some elementary sets, it is referred to as crisp (precise). On the contrary, if the concept cannot be presented in such a way, it is referred to as vague (imprecise, rough). $\underline{R} X$ is defined as the collection of cases whose equivalence classes are fully contained in the set of cases to approximate. $\bar{R} X$ is defined as the collection of cases whose equivalence classes are at least partially contained in (i.e. overlap with) the set of cases to approximate. So, there are five regions of interest: $\bar{R} X$ and $\underline{R} X$ and $\operatorname{POS}_{R}(X), B N_{R}(X)$ and $N E G_{R}(X)$. These sets are defined as shown below.

Let a set $X \subseteq U, R$ be an equivalence relation and knowledge. Two subsets base can be associated;

i) R-lower: $\underline{R} X=U\{Y \in U / R: Y \subseteq X\}$

ii) R-upper: $\bar{R} X=U\{Y \in U / R: Y \cap X \neq \phi\}$

It means that the elements belong to $\underline{R} X$ set can be classified with certainty as element of $X$; while the elements belong to $\bar{R} X$ set can be possibly classified as element of $X$. In the same way, $P O S_{R}(X), B N_{R}(X)$ and $N E G_{R}(X)$ are defined below

iii) $\operatorname{POS}_{R}(X)=\underline{R} X \Rightarrow$ certainly member of $X$

iv) $N E G_{R}(X)=U-\bar{R} X \Rightarrow$ certainly non member of $X$

v) $B N_{R}(X)=\bar{R} X-\underline{R} X \Rightarrow$ possibly member of $X$

\section{Reducts and Core}

The objective of data reduction is to find a minimal subset of relevant attributes that preserves the indiscernibility relation computed on the basis of the full set of attributes. Let $\mathbf{R}$ be a family of equivalence relations. The reduct of $\mathbf{R}, \operatorname{RED}(\mathbf{R})$, is defined as reduced set of relations that conserves the same inductive classification of set $\mathbf{R}$. It distinguishes all events which can be discernible by the original knowledge system. The core of $\mathbf{R}, \operatorname{CORE}(\mathbf{R})$, is the set of relations that appears in all reduct of $\mathrm{R}$, i.e., the set of all indispensable relations to characterize the relation $\mathbf{R}$. The concept of core and reducts are two fundamental concepts of Rough Set Theory and are important in the knowledge base reduction.

\section{Classification Process}

The algorithm of the whole classification procedure is shown in Fig. 2. All the steps in the algorithm are discussed one by one.

\section{Step-1: Extracting the Features from Wavelet Transform (WT)}

Power quality disturbances are simulated using MATLAB [16]. The sampling frequency considered is $6.4 \mathrm{kHz}$ i.e., 128 samples per cycle. Eleven types of power quality disturbances (or classes) are taken and are as follows:

$$
\begin{aligned}
& \mathrm{C}_{1} \rightarrow \text { Normal } \\
& \mathrm{C}_{2} \rightarrow \text { Pure Sag } \\
& \mathrm{C}_{3} \rightarrow \text { Pure Swell } \\
& \mathrm{C}_{4} \rightarrow \text { Momentary Interruption (MI) } \\
& \mathrm{C}_{5} \rightarrow \text { Harmonics } \\
& \mathrm{C}_{6} \rightarrow \text { Sag with Harmonic }
\end{aligned}
$$




$$
\begin{aligned}
& \mathrm{C}_{7} \rightarrow \text { Swell with Harmonic } \\
& \mathrm{C}_{8} \rightarrow \text { Flicker } \\
& \mathrm{C}_{9} \rightarrow \text { Notch } \\
& \mathrm{C}_{10} \rightarrow \text { Spike } \\
& \mathrm{C}_{11} \rightarrow \text { Transient }
\end{aligned}
$$

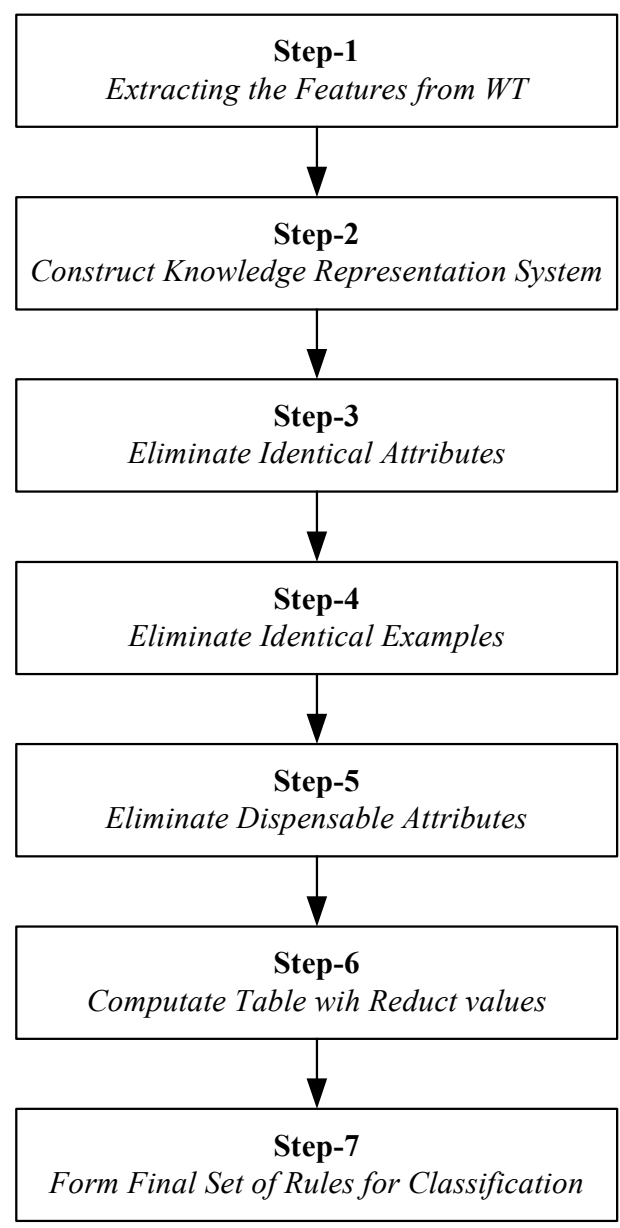

Fig. 2. Algorithm of classification process

The features of above mentioned PQ signals are extracted using Wavelet Transform (WT). The energy distribution at 13 detail decomposition levels $\left(\mathrm{D}_{1}-\mathrm{D}_{13}\right)$ [5-6] obtained through WT of the signal using dB4 wavelet are considered as the features. Hence there will be 13 features which are known as attributes in the knowledge representation system. Such 13 attributes are calculated for each class.

\section{Step-2: Formation of Knowledge Representation System}

In order to apply Rough Set Theory, the data has to be formatted in a particular fashion [10, 12]. The first attribute i.e., the energy distribution at $\mathrm{D}_{1}$ level is not considered while forming the knowledge representation system as for some of the classes it has very less value (of the order of $10^{-8}$ and $10^{-5}$ ) as compared to other features. Twelve different values $x_{2}$ to $x_{13}$ (Fig. 3) are generated. Based on the magnitude of attributes it will fall into a particular range. In order to get the values $x_{2}$ to $x_{13}$ and the number of ranges, many random numbers are generated and out of those thirteen values are considered to satisfy the non-overlapping condition of attributes for different classes. This will eliminate the problem of inconsistent data (inconsistent objects have identical values for their condition attributes but fall in different classes [17]). The knowledge about how the ranges are obtained is shown in Fig. 3. For example the range of $x_{2}$ (Fig. 3) is between 0-1 multiplied by a random number. A sample knowledge representation system (or decision table) is shown in Table 1 for pure sag $\left(\mathrm{C}_{2}\right)$ and harmonic $\left(\mathrm{C}_{5}\right)$ classes. In Table 1 , columns $\mathrm{D}_{2}-\mathrm{D}_{13}$ denote the range in which the corresponding attribute is falling and the last column shows the decision class. Therefore, the attribute value will now be the range number to which it is falling. 20 examples (or disturbances) of each class are considered in the classification process for the formation of rules.

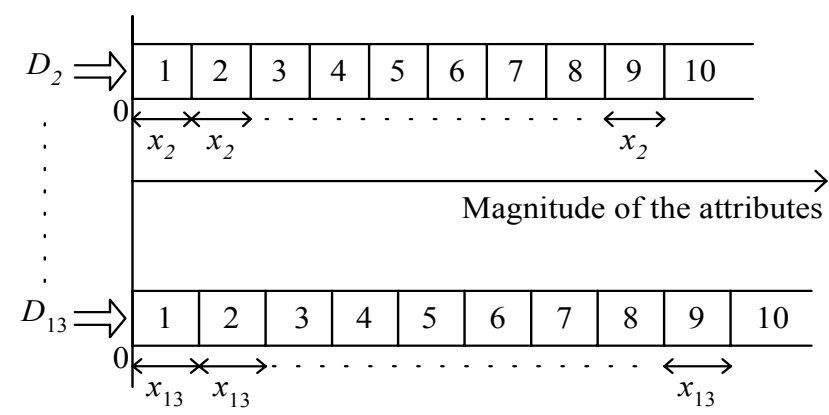

Fig. 3. Conversion of continuous data into ranges

\section{Step-3: Eliminate Identical Attributes}

In this step, if any attribute value is repeating, such repeating attribute is to be removed from the decision table. Attributes $D_{8}, D_{9}, D_{10}, D_{11}, D_{12}$ and $D_{13}$ belong to same range for all the examples of 11 classes. Since attribute values $D_{8}$ to $D_{13}$ are same any one of them can be considered and remaining can be removed for further analysis. Hence, $\mathrm{D}_{9}$ to $D_{13}$ are removed leaving $D_{8}$ as their representative in the classification algorithm.

\section{Step-4: Eliminate Identical Examples}

The identical examples of any particular class are to be removed as they are repeating in nature and may not be required for classification. For instance for class $\mathrm{C}_{2}$ examples $1,2,3,4,11,12,13$ are identical and hence repeating examples i.e., 2, 3, 4, 11, 12, 13 are to be removed from classification algorithm for further analysis.

\section{Step-5: Eliminate Dispensable Attributes}

In this step it is to be verified if the decision table contains only indispensable attributes. This task can be accomplished by eliminating each attribute step-by-step and verifying if the decision table gives the correct classification. For example, let us remove attribute $\mathrm{D}_{2}$ and see whether the decision table gives correct classification with remaining attributes. If the algorithm gives correct classification without $\mathrm{D}_{2}$, then it means that attribute $\mathrm{D}_{2}$ is not required for classification and hence it can be removed. Such attribute is called as a 
dispensable attribute for the decision table. Here $D_{2}$ is a dispensable attribute and hence it is eliminated for further analysis. Now consider attribute $\mathrm{D}_{3}$, and similar analysis is carried out to see whether $\mathrm{D}_{3}$ is dispensable. Similar procedure is repeated for other attributes. The attributes $D_{2}$ and $D_{8}$ are found to be dispensable attributes and are removed for further analysis. A sample decision table with indispensable attributes for classes $\mathrm{C}_{2}, \mathrm{C}_{3}$ and $\mathrm{C}_{4}$ is shown in Table 2 .

Table 1: A sample knowledge representation system

\begin{tabular}{|c|c|c|c|c|c|c|c|c|c|c|c|c|c|}
\hline Ex. & $\mathbf{D}_{2}$ & $\mathbf{D}_{3}$ & $\mathbf{D}_{4}$ & $\mathbf{D}_{5}$ & $\mathbf{D}_{6}$ & $\mathbf{D}_{7}$ & $\mathbf{D}_{8}$ & $\mathbf{D}_{9}$ & $\mathbf{D}_{10}$ & $\mathbf{D}_{11}$ & $D_{12}$ & $\mathbf{D}_{13}$ & $\begin{array}{c}\text { Decision } \\
\text { Class }\end{array}$ \\
\hline 1 & 1 & 1 & 6 & 4 & 5 & 8 & 1 & 1 & 1 & 1 & 1 & 1 & $\mathrm{C}_{2}$ \\
\hline 2 & 1 & 1 & 6 & 4 & 5 & 8 & 1 & 1 & 1 & 1 & 1 & 1 & $\mathrm{C}_{2}$ \\
\hline 3 & 1 & 1 & 6 & 4 & 5 & 8 & 1 & 1 & 1 & 1 & 1 & 1 & $\mathrm{C}_{2}$ \\
\hline 4 & 1 & 1 & 6 & 4 & 5 & 8 & 1 & 1 & 1 & 1 & 1 & 1 & $\mathrm{C}_{2}$ \\
\hline 5 & 1 & 1 & 6 & 4 & 5 & 9 & 1 & 1 & 1 & 1 & 1 & 1 & $\mathrm{C}_{2}$ \\
\hline 6 & 1 & 1 & 6 & 4 & 5 & 9 & 1 & 1 & 1 & 1 & 1 & 1 & $\mathrm{C}_{2}$ \\
\hline 7 & 1 & 1 & 5 & 4 & 5 & 9 & 1 & 1 & 1 & 1 & 1 & 1 & $\mathrm{C}_{2}$ \\
\hline 8 & 1 & 1 & 5 & 4 & 5 & 9 & 1 & 1 & 1 & 1 & 1 & 1 & $\mathrm{C}_{2}$ \\
\hline 9 & 1 & 1 & 5 & 4 & 5 & 9 & 1 & 1 & 1 & 1 & 1 & 1 & $\mathrm{C}_{2}$ \\
\hline 10 & 1 & 1 & 6 & 4 & 4 & 8 & 1 & 1 & 1 & 1 & 1 & 1 & $\mathrm{C}_{2}$ \\
\hline 11 & 1 & 1 & 6 & 4 & 5 & 8 & 1 & 1 & 1 & 1 & 1 & 1 & $\mathrm{C}_{2}$ \\
\hline 12 & 1 & 1 & 6 & 4 & 5 & 8 & 1 & 1 & 1 & 1 & 1 & 1 & $\mathrm{C}_{2}$ \\
\hline 13 & 1 & 1 & 6 & 4 & 5 & 8 & 1 & 1 & 1 & 1 & 1 & 1 & $\mathrm{C}_{2}$ \\
\hline 14 & 1 & 1 & 5 & 4 & 5 & 9 & 1 & 1 & 1 & 1 & 1 & 1 & $\mathrm{C}_{2}$ \\
\hline 15 & 1 & 1 & 6 & 4 & 4 & 7 & 1 & 1 & 1 & 1 & 1 & 1 & $\mathrm{C}_{2}$ \\
\hline 16 & 1 & 1 & 5 & 4 & 5 & 8 & 1 & 1 & 1 & 1 & 1 & 1 & $\mathrm{C}_{2}$ \\
\hline 17 & 1 & 1 & 5 & 4 & 5 & 9 & 1 & 1 & 1 & 1 & 1 & 1 & $\mathrm{C}_{2}$ \\
\hline 18 & 1 & 1 & 6 & 4 & 5 & 9 & 1 & 1 & 1 & 1 & 1 & 1 & $\mathrm{C}_{2}$ \\
\hline 19 & 1 & 1 & 5 & 4 & 5 & 9 & 1 & 1 & 1 & 1 & 1 & 1 & $\mathrm{C}_{2}$ \\
\hline 20 & 1 & 1 & 5 & 4 & 5 & 9 & 1 & 1 & 1 & 1 & 1 & 1 & $\mathrm{C}_{2}$ \\
\hline 21 & 1 & 2 & 7 & 4 & 5 & 10 & 1 & 1 & 1 & 1 & 1 & 1 & $\mathrm{C}_{5}$ \\
\hline 22 & 1 & 5 & 10 & 3 & 5 & 10 & 1 & 1 & 1 & 1 & 1 & 1 & $\mathrm{C}_{5}$ \\
\hline 23 & 1 & 7 & 10 & 2 & 5 & 10 & 1 & 1 & 1 & 1 & 1 & 1 & $\mathrm{C}_{5}$ \\
\hline 24 & 1 & 8 & 10 & 2 & 5 & 10 & 1 & 1 & 1 & 1 & 1 & 1 & $\mathrm{C}_{5}$ \\
\hline 25 & 1 & 10 & 10 & 2 & 5 & 10 & 1 & 1 & 1 & 1 & 1 & 1 & $\mathrm{C}_{5}$ \\
\hline 26 & 1 & 10 & 10 & 1 & 5 & 10 & 1 & 1 & 1 & 1 & 1 & 1 & $\mathrm{C}_{5}$ \\
\hline 27 & 1 & 10 & 10 & 2 & 5 & 10 & 1 & 1 & 1 & 1 & 1 & 1 & $\mathrm{C}_{5}$ \\
\hline 28 & 1 & 10 & 10 & 2 & 5 & 10 & 1 & 1 & 1 & 1 & 1 & 1 & $\mathrm{C}_{5}$ \\
\hline 29 & 2 & 10 & 10 & 2 & 5 & 10 & 1 & 1 & 1 & 1 & 1 & 1 & $\mathrm{C}_{5}$ \\
\hline 30 & 2 & 10 & 10 & 3 & 5 & 10 & 1 & 1 & 1 & 1 & 1 & 1 & $\mathrm{C}_{5}$ \\
\hline 31 & 2 & 10 & 10 & 4 & 5 & 10 & 1 & 1 & 1 & 1 & \begin{tabular}{|l|}
1 \\
\end{tabular} & 1 & $\mathrm{C}_{5}$ \\
\hline 32 & 2 & 10 & 10 & 4 & 5 & 10 & 1 & 1 & 1 & 1 & 1 & 1 & $\mathrm{C}_{5}$ \\
\hline 33 & 2 & 10 & 10 & 6 & 5 & 10 & 1 & 1 & 1 & 1 & 1 & 1 & $\mathrm{C}_{5}$ \\
\hline 34 & 2 & 10 & 10 & 6 & 5 & 10 & 1 & 1 & 1 & 1 & 1 & 1 & $\mathrm{C}_{5}$ \\
\hline 35 & 2 & 10 & 10 & 6 & 5 & 10 & 1 & 1 & 1 & 1 & 1 & 1 & $\mathrm{C}_{5}$ \\
\hline 36 & 2 & 10 & 10 & 7 & 5 & 10 & 1 & 1 & 1 & 1 & 1 & 1 & $\mathrm{C}_{5}$ \\
\hline 37 & 1 & 5 & 10 & 4 & 5 & 10 & 1 & 1 & 1 & 1 & 1 & 1 & $\mathrm{C}_{5}$ \\
\hline 38 & 1 & 10 & 10 & 3 & 5 & 10 & 1 & 1 & 1 & 1 & 1 & 1 & $\mathrm{C}_{5}$ \\
\hline 39 & 2 & 10 & 10 & 2 & 5 & 10 & 1 & 1 & 1 & 1 & 1 & 1 & $\mathrm{C}_{5}$ \\
\hline 40 & 2 & 10 & 10 & 2 & 5 & 10 & 1 & 1 & 1 & 1 & 1 & 1 & $\mathrm{C}_{5}$ \\
\hline
\end{tabular}

\section{Step-6: Compute Table with Reduct Values}

This is the most important step in Rough Set reduction technique as it gives minimal set of rules for the classification.

Let us calculate the reducts for Ex. 1. The procedure for obtaining reducts for Ex. 1 is given below:

From Table 2, there are five set of combinations of attributes leaving one column at a time

Set1: $\mathrm{D}_{4}(6)-\mathrm{D}_{5}(4)-\mathrm{D}_{6}(5)-\mathrm{D}_{7}(8)$

Set2: $\mathrm{D}_{3}(1)-\mathrm{D}_{5}(4)-\mathrm{D}_{6}(5)-\mathrm{D}_{7}(8)$

Set3: $\mathrm{D}_{3}(1)-\mathrm{D}_{4}(6)-\mathrm{D}_{6}(5)-\mathrm{D}_{7}(8)$

Set4: $\mathrm{D}_{3}(1)-\mathrm{D}_{4}(6)-\mathrm{D}_{5}(4)-\mathrm{D}_{7}(8)$

Set5: $\mathrm{D}_{3}(1)-\mathrm{D}_{4}(6)-\mathrm{D}_{5}(4)-\mathrm{D}_{6}(5)$ where the value inside the $(\bullet)$ represents the value of the attribute.

Table 2: A sample set of examples with indispensable attributes

\begin{tabular}{|c|c|c|c|c|c|c|}
\hline Ex. & $\mathbf{D}_{\mathbf{3}}$ & $\mathbf{D}_{\mathbf{4}}$ & $\mathbf{D}_{\mathbf{5}}$ & $\mathbf{D}_{\mathbf{6}}$ & $\mathbf{D}_{\mathbf{7}}$ & $\begin{array}{c}\text { Decision } \\
\text { Class }\end{array}$ \\
\hline $\mathbf{1}$ & $\mathbf{1}$ & 6 & $\mathbf{4}$ & $\mathbf{5}$ & $\mathbf{8}$ & $\mathbf{C}_{\mathbf{2}}$ \\
\hline 5 & 1 & 6 & 4 & 5 & 9 & $\mathrm{C}_{2}$ \\
\hline 7 & 1 & 5 & 4 & 5 & 9 & $\mathrm{C}_{2}$ \\
\hline 10 & 1 & 6 & 4 & 4 & 8 & $\mathrm{C}_{2}$ \\
\hline 15 & 1 & 6 & 4 & 4 & 7 & $\mathrm{C}_{2}$ \\
\hline $\mathbf{1 6}$ & $\mathbf{1}$ & 5 & $\mathbf{4}$ & $\mathbf{5}$ & $\mathbf{8}$ & $\mathbf{C}_{\mathbf{2}}$ \\
\hline 21 & 1 & 5 & 5 & 6 & 10 & $\mathrm{C}_{3}$ \\
\hline 23 & 1 & 6 & 5 & 6 & 10 & $\mathrm{C}_{3}$ \\
\hline 29 & 1 & 7 & 5 & 6 & 10 & $\mathrm{C}_{3}$ \\
\hline 36 & 1 & 7 & 5 & 7 & 10 & $\mathrm{C}_{3}$ \\
\hline 40 & 1 & 7 & 6 & 8 & 10 & $\mathrm{C}_{3}$ \\
\hline $\mathbf{4 1}$ & $\mathbf{1}$ & 7 & $\mathbf{4}$ & $\mathbf{5}$ & $\mathbf{8}$ & $\mathbf{C}_{\mathbf{4}}$ \\
\hline
\end{tabular}
$\mathrm{C}_{2}$ is

By referring to the Table 2, the decision category for class

$X \mathrm{C}_{2}=\{1,5,7,10,15,16\}$

Now check whether the attributes of above sets belong to the decision category $\mathrm{XC}_{2}$.

The attribute values of Set1 i.e., $\mathrm{D}_{4}(6)-\mathrm{D}_{5}(4)-\mathrm{D}_{6}(5)-\mathrm{D}_{7}(8)$ belong to Ex. 1 only (Table 2$)$ and can be expressed as

Set1: $\mathrm{D}_{4}(6) \cap \mathrm{D}_{5}(4) \cap \mathrm{D}_{6}(5) \cap \mathrm{D}_{7}(8)=\{1\}$

Since, Set1: $\mathrm{D}_{4}(6) \cap \mathrm{D}_{5}(4) \cap \mathrm{D}_{6}(5) \cap \mathrm{D}_{7}(8)=\{1\} \subset X \mathrm{C}_{2}$, this means that Set1 belong to the decision category $X \mathrm{C}_{2}$. Hence, set $\mathrm{D}_{4}(6)-\mathrm{D}_{5}(4)-\mathrm{D}_{6}(5)-\mathrm{D}_{7}(8)$ is one of the reducts of Ex.1.

Now consider the attribute Set2 i.e., $\mathrm{D}_{3}(1)-\mathrm{D}_{5}(4)-\mathrm{D}_{6}(5)-$ $\mathrm{D}_{7}(8)$. The attributes of Set 2 belong to Ex. 1, 16, 41 and can be expressed as

Set2: $\mathrm{D}_{3}(1) \cap \mathrm{D}_{5}(4) \cap \mathrm{D}_{6}(5) \cap \mathrm{D}_{7}(8)=\{1,16,41\} \not \subset X \mathrm{C}_{2}$ This is highlighted in Table 2 also by the bold letters. As seen in the Table 2, Ex. 41 belongs to class $\mathrm{C}_{4}$ and hence Set 2 does not belong to the decision category $X C_{2}$ and set $\mathrm{D}_{3}(1)-\mathrm{D}_{5}(4)-$ $\mathrm{D}_{6}(5)-\mathrm{D}_{7}(8)$ is not a reduct of Ex.1.

Similarly check for Set3, Set4 and Set5.

Set3: $\mathrm{D}_{3}(1) \cap \mathrm{D}_{4}(6) \cap \mathrm{D}_{6}(5) \cap \mathrm{D}_{7}(8)=\{1\} \subset X \mathrm{C}_{2}$

Set4: $\mathrm{D}_{3}(1) \cap \mathrm{D}_{4}(6) \cap \mathrm{D}_{5}(4) \cap \mathrm{D}_{7}(8)=\{1,10\} \subset X \mathrm{C}_{2}$

Set5: $\mathrm{D}_{3}(1) \cap \mathrm{D}_{4}(6) \cap \mathrm{D}_{5}(4) \cap \mathrm{D}_{6}(5)=\{1,5\} \subset X \mathrm{C}_{2}$

Since Set1, Set3, Set4, Set5 belong to the decision category $X \mathrm{C}_{2}$, these sets will be the reducts of Ex.1. Hence, there are four reducts of Ex. 1 and are given as

Reduct-1: $\mathrm{D}_{4}(6)-\mathrm{D}_{5}(4)-\mathrm{D}_{6}(5)-\mathrm{D}_{7}(8)$

Reduct-2: $\mathrm{D}_{3}(1)-\mathrm{D}_{4}(6)-\mathrm{D}_{6}(5)-\mathrm{D}_{7}(8)$

Reduct-3: $\mathrm{D}_{3}(1)-\mathrm{D}_{4}(6)-\mathrm{D}_{5}(4)-\mathrm{D}_{7}(8)$

Reduct-4: $\mathrm{D}_{3}(1)-\mathrm{D}_{4}(6)-\mathrm{D}_{5}(4)-\mathrm{D}_{6}(5)$

In the similar way reducts of remaining examples belonging to class $\mathrm{C}_{2}$ are calculated and they are given in Table 3 . 
The reducts of all the examples present in the decision table after step-5 are analyzed to form the final set of classification rules.

\section{Step-7: Formation of final set of rules for classification}

After computing reducts, classification rules can be developed from the reducts. The if-then rules are constructed by making "AND" operation on the row values and "OR" operation on the column values of reduct table. For example, the if-then rule for classification of class $\mathrm{C}_{2}$ from the reducts given in Table 3 is written as follows:

If

$\left(\mathrm{D}_{3}==1\right)$ AND $\left(\mathrm{D}_{4}==6 \boldsymbol{O R} \mathrm{D}_{4}==5\right)$ AND $\left(\mathrm{D}_{5}==4\right)$ AND $\left(\mathrm{D}_{6}==5 \boldsymbol{O} \boldsymbol{R} \mathrm{D}_{6}==4\right) \mathbf{A N D}\left(\mathrm{D}_{7}==8 \boldsymbol{O} \boldsymbol{R} \mathrm{D}_{7}==9 \boldsymbol{O} \boldsymbol{R}\right.$ $\left.\mathrm{D}_{7}==7\right)$

Then

Class $=\mathrm{C}_{2}$ (i.e., Pure Sag)

Table 3: A set of reducts for decision class $\mathrm{C}_{2}$

\begin{tabular}{|c|c|c|c|c|c|c|}
\hline Ex. & $\mathbf{D}_{3}$ & $\mathbf{D}_{4}$ & $\mathbf{D}_{5}$ & $D_{6}$ & $\mathbf{D}_{7}$ & $\begin{array}{c}\text { Decision } \\
\text { Class }\end{array}$ \\
\hline \multirow{4}{*}{1} & - & 6 & 4 & 5 & 8 & \multirow{4}{*}{$\mathrm{C}_{2}$} \\
\hline & 1 & 6 & - & 5 & 8 & \\
\hline & 1 & 6 & 4 & - & 8 & \\
\hline & 1 & 6 & 4 & 5 & - & \\
\hline \multirow{4}{*}{5} & 1 & - & 4 & 5 & 9 & \multirow{4}{*}{$\mathrm{C}_{2}$} \\
\hline & 1 & 6 & - & 5 & 9 & \\
\hline & 1 & 6 & 4 & - & 9 & \\
\hline & 1 & 6 & 4 & 5 & - & \\
\hline \multirow{4}{*}{7} & 1 & - & 4 & 5 & 9 & \multirow{4}{*}{$\mathrm{C}_{2}$} \\
\hline & 1 & 5 & - & 5 & 9 & \\
\hline & 1 & 5 & 4 & - & 9 & \\
\hline & 1 & 5 & 4 & 5 & - & \\
\hline \multirow{4}{*}{10} & - & 6 & 4 & 4 & 8 & \multirow{4}{*}{$\mathrm{C}_{2}$} \\
\hline & 1 & 6 & - & 4 & 8 & \\
\hline & 1 & 6 & 4 & - & 8 & \\
\hline & 1 & 6 & 4 & 4 & - & \\
\hline \multirow{5}{*}{15} & - & 6 & 4 & 4 & 7 & \multirow{5}{*}{$\mathrm{C}_{2}$} \\
\hline & 1 & - & 4 & 4 & 7 & \\
\hline & 1 & 6 & - & 4 & 7 & \\
\hline & 1 & 6 & 4 & - & 7 & \\
\hline & 1 & 6 & 4 & 4 & - & \\
\hline \multirow{4}{*}{16} & - & 5 & 4 & 5 & 8 & \multirow{4}{*}{$\mathrm{C}_{2}$} \\
\hline & 1 & 5 & - & 5 & 8 & \\
\hline & 1 & 5 & 4 & - & 8 & \\
\hline & 1 & 5 & 4 & 5 & - & \\
\hline
\end{tabular}

Rules are written for other remaining classes from the reducts of corresponding examples belonging to that particular class. Rules for classes $\mathrm{C}_{4}$ (i.e., Momentary Interruption) and $\mathrm{C}_{8}$ (i.e., Flicker) are given below. For simplicity rules of only 3 classes are specified here.
If

$\left(\mathrm{D}_{3}==1\right)$ AND $\left(\mathrm{D}_{4}==7\right)$ AND $\left(\mathrm{D}_{5}==4\right)$ AND $\left(\mathrm{D}_{6}==5\right.$

OR $\left.\mathrm{D}_{6}==4\right)$ AND $\left(\mathrm{D}_{7}==8\right)$

Then

Class $=\mathrm{C}_{4}$ (i.e., Momentary Interruption)

If

$\left(\mathrm{D}_{6}==1\right)$

Then

Class $=\mathrm{C}_{8}$ (i.e., Flicker)

Hence after rough set analysis (step-2 to step-7), it is concluded that through only 5 attributes $\left(\mathrm{D}_{3}, \mathrm{D}_{4}, \mathrm{D}_{5}, \mathrm{D}_{6}\right.$ and $\mathrm{D}_{7}$ ), correct and effective classification of PQ disturbances is achieved.

\section{Testing Results}

Once classification rules are framed, the unknown input data can be tested for classification through those rules. The testing data is converted into same number of ranges as done during classification process (Section III). The attributes required for classification are only $\mathrm{D}_{3}, \mathrm{D}_{4}, \mathrm{D}_{5}, \mathrm{D}_{6}$ and $\mathrm{D}_{7}$ which we get after step-5 (Section III). The 1,100 PQ events (100 for each disturbance) are tested for the classification and testing results are shown in Table 4. The diagonal elements represent correctly classified PQ classes. The off-diagonal elements represent the misclassification and unidentification of classes. The unidentified results are shown in Table 4 by column $U$ (do not belong to any class). The overall accuracy is calculated by finding the average of all diagonal elements and found to be $95.5 \%$ (Table 4).

The unidentified results (shown by column $U$ in Table 4) can be debug by taking into classification process and get a new set of classification rules. This will further enhance the classification accuracy.

Table 4: Classification results

\begin{tabular}{c|c|c|c|c|c|c|c|c|c|c|c|c}
\hline & $\mathrm{C}_{1}$ & $\mathrm{C}_{2}$ & $\mathrm{C}_{3}$ & $\mathrm{C}_{4}$ & $\mathrm{C}_{5}$ & $\mathrm{C}_{6}$ & $\mathrm{C}_{7}$ & $\mathrm{C}_{8}$ & $\mathrm{C}_{9}$ & $\mathrm{C}_{10}$ & $\mathrm{C}_{11}$ & $\mathrm{U}$ \\
\hline $\mathrm{C}_{1} \rightarrow$ & $\mathbf{1 0 0}$ & 0 & 0 & 0 & 0 & 0 & 0 & 0 & 0 & 0 & 0 & 0 \\
\hline $\mathrm{C}_{2} \rightarrow$ & 0 & $\mathbf{1 0 0}$ & 0 & 0 & 0 & 0 & 0 & 0 & 0 & 0 & 0 & 0 \\
\hline $\mathrm{C}_{3} \rightarrow$ & 0 & 0 & $\mathbf{9 7}$ & 0 & 0 & 0 & 0 & 0 & 0 & 0 & 0 & 3 \\
\hline $\mathrm{C}_{4} \rightarrow$ & 0 & 0 & 0 & $\mathbf{1 0 0}$ & 0 & 0 & 0 & 0 & 0 & 0 & 0 & 0 \\
\hline $\mathrm{C}_{5} \rightarrow$ & 0 & 0 & 0 & 0 & $\mathbf{9 0}$ & 0 & 0 & 0 & 2 & 8 & 0 & 0 \\
\hline $\mathrm{C}_{6} \rightarrow$ & 0 & 0 & 0 & 1 & 3 & $\mathbf{9 2}$ & 0 & 0 & 2 & 0 & 0 & 2 \\
\hline $\mathrm{C}_{7} \rightarrow$ & 0 & 0 & 0 & 0 & 0 & 0 & $\mathbf{9 6}$ & 0 & 0 & 2 & 0 & 2 \\
\hline $\mathrm{C}_{8} \rightarrow$ & 0 & 0 & 0 & 0 & 0 & 0 & 0 & $\mathbf{1 0 0}$ & 0 & 0 & 0 & 0 \\
\hline $\mathrm{C}_{9} \rightarrow$ & 0 & 1 & 0 & 0 & 0 & 5 & 0 & 0 & $\mathbf{9 4}$ & 0 & 0 & 0 \\
\hline $\mathrm{C}_{10} \rightarrow$ & 0 & 0 & 0 & 0 & 7 & 0 & 0 & 0 & 3 & $\mathbf{9 0}$ & 0 & 0 \\
\hline $\mathrm{C}_{11} \rightarrow$ & 0 & 0 & 0 & 0 & 2 & 0 & 0 & 0 & 3 & 0 & $\mathbf{9 1}$ & 4 \\
\hline
\end{tabular}

Overall Accuracy: $95.5 \%$

$\mathrm{U} \rightarrow$ Unidentified 


\section{CONCLUSIONS}

In this paper a new technique is presented for classification of power quality (PQ) disturbance signals based on Rough Set technique. The proposed method gives rule based classification which is very easy to understand and simple to implement. The features of PQ disturbances are extracted by using Wavelet Transform and then these features are reduced by rough set reduction technique. With reduced features, reduct values are calculated and subsequently classification rules are framed. Since rough set analysis reduces the attributes to great extent, certainly memory requirement will reduce.

The 1,100 PQ disturbances (100 for each disturbance) are tested for the classification and overall accuracy is found to be $95.5 \%$. Some results during testing are found to be unidentified which can be analyzed by taking into classification process and get a new set of rules. This will further enhance the classification accuracy.

\section{REFERENCES}

[1] A. M. Gaouda, M.M.A. Salama, M. K. Sultan and A.Y. Chikhani, "Power Quality Detection and Classification Using WaveletMultiresolution Signal Decomposition", IEEE Transactions on Power Delivery, vol. 14, no. 4, pp. 1469-1476, Oct. 1999.

[2] L. Angrisani, P. Daponte, M. D'Apuzzo, and A. Testa, "A measurement method based on the wavelet transform for power quality analysis," IEEE Transactions on Power Delivery, vol. 13, no. 4, pp. 990-998, Oct. 1998.

[3] S. Santoso, E. J. Powers, and W. Grady "Power quality disturbance identification using wavelet transforms and artificial neutral network", The 1996 International Conference on Harmonic and Quality of Power, pp. 615-618, Las Vegas, NV, U.S.A, 1996.

[4] S. Santoso, E. J. Powers, W. Grady and A. C. Parsons "Power quality disturbance waveform recognition using wavelet-based neutral classifier-part 1/part 2", IEEE Transactions on Power Delivery, vol. 15, no. 1, pp. 222-235, Jan. 2000.

[5] Z. L. Gaing, "Wavelet-Based Neural Network for Power Disturbance Recognition and Classification", IEEE Trans. on Power Delivery, vol. 19, no.4, pp. 1560-1568, Oct. 2004.

[6] Haibo He and J. A. Starzyk, "A Self-Organizing Learning Array System for Power Quality Classification Based on Wavelet Transform", IEEE Trans. on Power Delivery, vol. 21, no.1, pp. 286-295, Jan. 2006.

[7] Z. Pawlak, "Rough Sets- Theoretical Aspects of Reasoning about Data", Kluwer Academic Publisher, 1991.

[8] C. L. Hor, P. A. Crossley, "Unsupervised Event Extraction Within Substations Using Rough Classification, IEEE Trans. on Power Delivery, vol. 21, no.4, pp. 1809-1816, Oct. 2006.

[9] C. I. F. Agreira, C. M. M. Ferreira, J. A. D. Pinto and F. P. M. Barbosa, "Electric Power Systems Steady-State Security Assessment Using the Rough Theory", International Conference on Probabilistic Methods Applied to Power Systems, pp. 873-877, 12-16 Sept. 2004.

[10] G. L. Torres, "Application of Rough Sets in Power System Control Centre Data Mining," IEEE Power Engineering Society Winter Meeting, 2002, vol. 1, pp. 627-631, Jan. 2002.

[11] Xiuping Xu; J. F. Peters, "Rough set methods in power system fault classification", Canadian Conference on Electrical and Computer Engineering (IEEE CCECE 2002), vol. 1, pp. 100-105, 12-15 May 2002.

[12] G. L. Torres, A. P. A. da Silva, V. H. Quintana and L. E. B. da Silva, "Classification of power system operation point using rough set techniques", IEEE International Conference on Systems, Man, and Cybernetics, vol. 3, pp. 1898-1903, 14-17 Oct. 1996.

[13] I. Daubechies, "Ten lectures on wavelets", Philadelphia, PA: Society for Industrial and Applied Mathematics, 1992.

[14] C. S. Burrus, R. A. Gopinath, and H. Guo, Introduction to Wavelets and Wavelet Transforms: A Primer. Englewood Cliffs, NJ: Prentice-Hall, 1998.
[15] S. Mallat, "A theory for multiresolution signal decomposition: The wavelet representation", IEEE Trans. Pattern Anal. and Mach. Intell., vol. 11, no. 7, pp. 674-693, July 1989.

[16] MATLAB, Math Works, Inc., Natick, MA, USA, 2000.

[17] Y. Sai, P. Nie, R. Xu and J. Huang, "A Rough Set Approach to Mining Concise Rules from Inconsistent Data”, IEEE International Conference on Granular Computing, pp. 333-336, 10-12 May 2006.

C. N. Bhende received BE degree from Nagpur University (RKNEC),

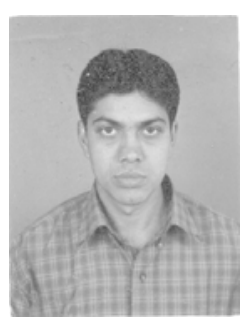
Nagpur, India, M. Tech degree from Visvesvaraya National Institute of Technology, Nagpur, India (Formerly VRCE) and PhD degree from Department of Electrical Engineering, Indian Institute of Technology- Delhi, India in 1999, 2003 and 2008 respectively. He is currently working as Post-Doctoral Research Fellow in the School of Electrical, Computer \& Telecommunication Engg. (SECTE), University of Wollongong, Australia. His field of interest includes wind plus hybrid generation, power quality aspects, application of power electronics to power system and application of soft computing techniques.

S. Mishra received BE degree from University College of Engineering, Burla, Orissa, India and M.E. and $\mathrm{PhD}$ degree from

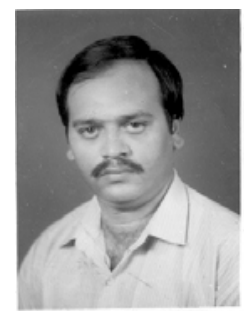
Regional Engineering College, Rourkela, Orissa, India, in 1990 and 1992 and 2000 respectively. In 1992, he joined the department of Electrical Engineering, University College of Engineering, Burla, as a lecturer and subsequently became a reader in 2001. Presently he is a faculty at the department of Electrical Engineering, Indian Institute of Technology, Delhi, India. He has been honored with many prestigious awards such as INSA Young Scientist Medal-2002, INAE Young Engineer's award-2002, recognition as DST Young Scientist 2001-2002, etc. His interests are in fuzzy logic and ANN applications to power system control and power quality. 